\title{
Qualidade físico-química e de fritura de tubérculos de cultivares de batata na safra de inverno
}

\author{
Adalton M Fernandes ${ }^{1}$; Rogério P Soratto ${ }^{1}$; Regina Marta Evangelista ${ }^{2}$; Israel Nardin ${ }^{3}$ \\ ${ }^{1}$ UNESP-FCA, Depto. Prod. Vegetal (Agricultura), C. Postal 237, 18610-307 Botucatu-SP; ${ }^{2}$ UNESP-FCA, Depto. Gestão e Tecnologia \\ Agroindustrial; ${ }^{3}$ UNESP-FCA, Progr. Pós-graduação Lato Sensu em Ciência e Tecnologia de Alimentos; soratto@fca.unesp.br
}

\begin{abstract}
RESUMO
Com o aumento do consumo de batata processada na forma de fritura, torna-se essencial a identificação dos parâmetros de qualidade dos tubérculos de batata. Objetivou-se avaliar a composição físicoquímica e qualidade de fritura de tubérculos de cultivares de batata, produzidos na safra de inverno. Os tubérculos foram provenientes de experimento de campo conduzido durante a safra de inverno de 2008, no município de Itaí-SP. O delineamento experimental utilizado foi blocos casualizados, com quatro repetições e cinco tratamentos, representados pelas cultivares Agata, Asterix, Atlantic, Markies e Mondial. Os tubérculos das cultivares Mondial e Agata apresentaram características adequadas para o mercado fresco, sendo indicadas para a preparação de massas e pratos assados em que é essencial a manutenção de sua forma. Markies apresentou dupla aptidão culinária, ou seja, possui qualidade adequada ao preparo de massas e fritura. Os tubérculos das cultivares Atlantic, Asterix e Markies apresentaram boa qualidade de fritura, no entanto, a cultivar Markies apresentou polpa dos tubérculos, palitos e chips de coloração amarela mais intensa.
\end{abstract}

Palavras-chave: Solanum tuberosum, matéria seca, açúcares redutores, cor da polpa, cor do chips.

\begin{abstract}
Physicochemical and frying quality of potato cultivars in winter season

Given the raising consumption of potato chips, the identification of quality parameters of potato tubers has become essential. The purpose of this work was to evaluate the physicochemical characteristics and frying quality of potato tubers of different cultivars grown in the winter cropping season. Tubers were obtained from a field experiment in the winter season in Itaí, São Paulo State, Brazil. The experimental design was of completely randomized blocks with four replications. Treatments consisted of five potato cultivars (Agata, Asterix, Atlantic, Markies and Mondial). Tubers of Mondial and Agata cultivars showed suitable characteristics for fresh market, so they can be recommended for the preparation of pasta and baked dishes, for which the preservation of the tuber shape is essential. Markies showed double cooking ability, i.e., suitable for preparation of pasta as well as for frying. The tubers of Atlantic, Asterix and Markies cultivars presented good frying quality, however, Markies cultivar showed pulp, sticks and chips with more intense yellow color.
\end{abstract}

Keywords: Solanum tuberosum, dry matter, reducing sugars, flesh colour, chips colour.

(Recebido para publicação em 26 de outubro de 2009; aceito em 16 de agosto de 2010) (Received on October 26, 2009; accepted on August 16, 2010)

\begin{abstract}
$\mathrm{A}^{\mathrm{b}}$ batata (Solanum tuberosum L.) é a hortaliça de maior importância econômica no Brasil, sendo comercializada quase que exclusivamente na forma in natura (Zorzella et al., 2003). Nos pontos de venda, o consumidor escolhe tubérculos prioritariamente pelo formato, por características visuais como cor e brilho da pele, e pelo preço de aquisição, se interessando pouco pelas características de qualidade e composição interna.

A procura de informações por parte dos consumidores no que diz respeito à adequada forma de preparo e utilização da batata tem sido cada vez maior (Feltran et al., 2004). A qualidade interna da batata é determinada pela composição química dos tubérculos (Moreno, 2000), que sofre influência principalmente do manejo da adubação e da cultivar empregada (Quadros et al.,
\end{abstract}

2009). Bregagnoli (2006) relata que a classificação da batata em relação à sua aptidão de uso (fritura, cozimento ou massa) é dependente das características bromatológicas dos tubérculos.

Com a redução do consumo de batata adquirida na forma in natura e aumento considerável do consumo de batata processada industrialmente, na forma de fritura, durante a última década em muitos países (Andreu et al., 2007), torna-se essencial a identificação dos parâmetros de qualidade dos tubérculos de batata.

Neste contexto, a composição química e bioquímica dos tubérculos é importante não somente para determinar a qualidade da batata, mas também a qualidade do produto final. Características como o conteúdo de açúcares redutores e o teor de matéria seca interferem na qualidade e coloração do produto final, sendo dessa forma, consideradas como parâmetros de qualidade da batata para fritura (Zorzella et al., 2003). Além disso, o teor de matéria seca está diretamente relacionado com o rendimento de fritura e a textura do produto processado, pois influencia a absorção de óleo durante o processo de fritura (Pereira, 2003).

Altos teores de açúcares redutores causam escurecimento indesejável da batata durante a fritura, reduzindo a aceitação comercial. Outros fatores como $\mathrm{pH}$ da polpa, acidez e conteúdo de amido podem interferir de forma indireta na qualidade tecnológica dos tubérculos (Feltran et al., 2004).

As características físicas e bioquímicas dos tubérculos sofrem influência do ambiente, porém, tendem a ser constan- 
tes em uma mesma cultivar (Salamoni et al., 2000). Assim, cada cultivar possui características especiais, o que evidencia a importância de identificá-las em relação a sua melhor forma de utilização. Dessa forma, o objetivo desse trabalho foi avaliar a qualidade físico-química para fritura de tubérculos de cultivares de batata, produzidos durante a safra de inverno.

\section{MATERIAL E MÉTODOS}

Tubérculos da classe graúda de cinco cultivares de batata produzidos durante a safra de inverno de 2008 em área produtora de batata no município de Itaí, SP (2328' S; 4908' W) foram usados no presente trabalho. No campo, o plantio foi realizado manualmente, em 8/6/2008, no espaçamento de $0,80 \mathrm{~m}$ entre fileiras e 0,35 m entre plantas. Aos 97 dias após o plantio (DAP) quando as plantas entraram no início do estádio de senescência, ou seja, quando iniciou-se o amarelecimento das folhas, realizou-se a dessecação da parte aérea de todas as cultivares com o herbicida Diquat (330 g do i.a. ha ${ }^{-1}$ ). Os tubérculos das linhas centrais de cada parcela foram colhidos 25 dias após a dessecação da parte aérea das plantas, para as determinações das características físico-químicas.

O delineamento experimental seguiu o experimento de campo, ou seja, blocos ao acaso, com quatro repetições e cinco tratamentos, representados pelas cultivares de batata Agata, Asterix, Atlantic, Markies e Mondial.

Para as avaliações físico-químicas foram utilizados quatro tubérculos da classe graúda proveniente de cada unidade experimental do campo. Foram avaliados: firmeza, sólidos solúveis, acidez titulável, $\mathrm{pH}$ da polpa, cinzas, teor de fibras totais, teor de matéria seca, teor de açúcares totais e redutores, teor de amido, cor da polpa e cor das fritas na forma de palito e chips.

A firmeza foi determinada em cada um dos quatro tubérculos (com casca) de cada unidade experimental, utilizandose texturômetro (Stevens - LFRA Texture Analyser) com profundidade de penetração de $20 \mathrm{~mm}$ e velocidade de $2,0 \mathrm{~mm} \mathrm{~s}^{-1}$ e ponteiro TA 9/1000. Na quantificação dos sólidos solúveis algumas fatias da polpa foram maceradas e duas gotas do suco foram colocadas no prisma do refratômetro eletrônico (Atago, modelo PR32), e após um minuto fez-se a leitura direta dos graus Brix. Para a determinação da acidez titulável, $50 \mathrm{~g}$ de polpa foram trituradas com 100 $\mathrm{mL}$ de água destilada e a mistura foi filtrada e titulada com solução hidróxido de sódio a $0,1 \mathrm{~N}$, tendo como indicador fenolftaleína (Brasil, 2005). Com os dados de acidez e ${ }^{\circ}$ Brix calculou-se a relação entre o teor de sólidos solúveis e a acidez titulável (SS/AT).

A determinação do $\mathrm{pH}$ foi realizada com $50 \mathrm{~g}$ de polpa, as quais foram trituradas em $100 \mathrm{~mL}$ de água destilada, e nestas fez-se a leitura direta do $\mathrm{pH}$, com medidor de $\mathrm{pH}$ digital (Digimed, modelo DM-2). O teor de matéria seca foi determinado pelo método gravimétrico a $105^{\circ} \mathrm{C}$ em estufa com circulação de ar até peso constante (Brasil, 2005), e as cinzas foram determinadas pela calcinação em mufla a $550^{\circ} \mathrm{C}$, de acordo com o método 942.05 da AOAC (2000). A metodologia utilizada para a determinação de fibra alimentar total, nos tubérculos de batata foi a proposta pela AOAC (1997).

Os teores de açúcares totais, redutores e amido foram determinados na matéria seca, segundo metodologia descrita por Somogyi, adaptada por Nelson (1944) e as leituras realizadas em espectrofotômetro a $535 \mathrm{~nm}$, e os dados de açúcares convertidos para teores na matéria fresca.

A qualidade de fritura foi avaliada pela coloração das batatas após o processamento na forma de palitos e chips. Para isso, um tubérculo de cada unidade experimental (repetição) foi utilizado para formar uma amostra de cada cultivar. Os tubérculos foram processados na forma de chips e palitos. A fritura foi feita em óleo de soja refinado durante 3 minutos em fogão doméstico, sendo a temperatura do óleo monitorada com termômetro e as batatas processadas postas para fritar quando a temperatura do óleo atingiu $180^{\circ} \mathrm{C}$. A proporção de óleo foi de 10:1, ou seja, $1 \mathrm{~L}$ de óleo para cada 100 gramas de batata. Essa proporção minimizou a queda de temperatura quando as batatas foram imersas no óleo a $180^{\circ} \mathrm{C}$. A coloração das batatas fritas e da polpa nos tubérculos frescos foram determinadas pelo método instrumental em cinco pontos de cada amostra, utilizando-se o colorímetro digital (Minolta CR-400), com determinação dos valores $L^{*}$ (indica luminosidade), $a^{*}$ (indica variação de cor do verde até o vermelho) e $b^{*}$ (indica variação de cor do azul até o amarelo) (Papadakis et al., 2000). Com os valores de $a^{*}$ e $b^{*}$ calculou-se o ângulo hue $\left({ }^{\circ} h=\tan ^{-1}\left(b^{*} / a^{*}\right)\right)$, que define a tonalidade de cor, e o chroma

$$
\left(C^{*}=\sqrt{\left(a^{*}\right)^{2}+\left(b^{*}\right)^{2}}\right),
$$

que define a intensidade da cor (Mcguire, 1992).

Os resultados foram submetidos à análise de variância e as médias comparadas pelo teste de Tukey a 5\% de probabilidade. Foram realizadas análises de correlação simples entre as características físico-químicas dos tubérculos, visando determinar o grau de associação entre elas.

\section{RESULTADOS E DISCUSSÃO}

As cultivares Asterix, Markies e Mondial apresentaram polpa mais firme quando comparada às demais, sendo que a cultivar Agata apresentou polpa com menor firmeza (Tabela 1). Feltran et al. (2004) também observaram diferenças significativas entre as cultivares Asterix $(8,15 \mathrm{~N})$ e Agata $(6,74 \mathrm{~N})$, quanto aos valores de firmeza da polpa. Cultivares que possuem polpa mais firme e amarelas são indicadas para preparo de massas (Pereira et al., 2005).

Os valores de sólidos solúveis ( ${ }^{\circ}$ Brix) foram maiores nos tubérculos das cultivares Atlantic e Markies, que diferiram das demais cultivares (Tabela 1). De acordo com Chitarra \& Chitarra (2005), os sólidos solúveis são constituídos principalmente por açúcares (sacarose), o que pode ser confirmado com as correlações positivas dessa variável com os teores de açúcares totais $(\mathrm{r}=0,54 ; p<0,01)$ e redutores $(\mathrm{r}=0,58$; $p<0,01$ ). Robles (2003) observou valores de ${ }^{\circ}$ Brix variando de 5,88 a 5,93 em tubérculos da cultivar Atlantic. Feltran et al. (2004) não observaram diferenças em tubérculos das cultivares Agata $(5,46)$, 
Tabela 1. Firmeza, sólidos solúveis, acidez titulável, relação sólidos solúveis/acidez titulável (SS/AT) e pH da polpa em tubérculos de cultivares de batata, produzidos na safra de inverno (firmness, soluble solids, titratable acidity, soluble solids/titratable acidity ratio (SS/ AT) and pulp pH in potato cultivars produced in the winter cropping season). Botucatu, FCA-UNESP, 2008.

\begin{tabular}{lccccc}
\hline Cultivares & Firmeza (N) & $\begin{array}{c}\text { Sólidos solúveis } \\
\text { ('Brix) }\end{array}$ & $\begin{array}{c}\text { Acidez titulável } \\
\text { (\% ácido cítrico) }\end{array}$ & $\begin{array}{c}\text { Sólidos solúveis/ } \\
\text { acidez titulável }\end{array}$ & pH da polpa \\
\hline Agata & $6,72 \mathrm{c}$ & $4,32 \mathrm{~b}$ & $0,20 \mathrm{a}$ & $24,22 \mathrm{bc}$ & $6,10 \mathrm{c}$ \\
Asterix & $9,31 \mathrm{a}$ & $4,25 \mathrm{~b}$ & $0,17 \mathrm{a}$ & $24,68 \mathrm{abc}$ & $6,18 \mathrm{bc}$ \\
Atlantic & $8,05 \mathrm{~b}$ & $5,05 \mathrm{a}$ & $0,20 \mathrm{a}$ & $29,23 \mathrm{ab}$ & $6,33 \mathrm{ab}$ \\
Markies & $9,08 \mathrm{a}$ & $5,27 \mathrm{a}$ & $0,20 \mathrm{a}$ & $29,55 \mathrm{a}$ & $6,40 \mathrm{a}$ \\
Mondial & $8,88 \mathrm{a}$ & $3,95 \mathrm{~b}$ & $0,20 \mathrm{a}$ & $22,50 \mathrm{c}$ & $6,06 \mathrm{c}$ \\
\hline $\mathrm{CV}(\%)$ & 4,10 & 4,41 & 9,13 & 8,72 & 1,43 \\
\hline
\end{tabular}

Médias seguidas de mesma letra nas colunas não diferem entre si pelo teste Tukey a 5\% de probabilidade de erro (means followed by the same letter, in column, do not differ by the Tukey test at $5 \%$ of probability).

Tabela 2. Teores de matéria seca, amido, açúcares totais e açúcares redutores, fibra total e cinzas em tubérculos de cultivares de batata, produzidos na safra de inverno (dry matter, starch, total sugars, reducing sugars, fibers and ashes content of the tubers of potato cultivars produced in the winter cropping season). Botucatu, FCA-UNESP, 2008.

\begin{tabular}{lcccccc}
\hline Cultivares & $\begin{array}{c}\text { Matéria seca } \\
(\mathbf{\%})\end{array}$ & $\begin{array}{c}\text { Amido (base } \\
\text { seca) }(\%)\end{array}$ & $\begin{array}{c}\text { Açúcares } \\
\text { totais }^{1}\end{array}$ & $\begin{array}{c}\text { Açúcares } \\
\text { redutores }^{\mathbf{1}}\end{array}$ & Fibra total $^{\mathbf{1}}$ & Cinzas $^{\mathbf{1}}$ \\
\hline Agata & $14,10 \mathrm{c}$ & $72,20 \mathrm{~b}$ & $0,12 \mathrm{~b}$ & $0,10 \mathrm{ab}$ & $0,60 \mathrm{a}$ & $0,79 \mathrm{c}$ \\
Asterix & $16,70 \mathrm{~b}$ & $78,20 \mathrm{ab}$ & $0,25 \mathrm{a}$ & $0,17 \mathrm{a}$ & $0,54 \mathrm{a}$ & $0,91 \mathrm{~b}$ \\
Atlantic & $19,00 \mathrm{a}$ & $84,80 \mathrm{a}$ & $0,19 \mathrm{ab}$ & $0,12 \mathrm{ab}$ & $0,53 \mathrm{a}$ & $1,02 \mathrm{a}$ \\
Markies & $17,20 \mathrm{ab}$ & $74,40 \mathrm{ab}$ & $0,30 \mathrm{a}$ & $0,18 \mathrm{a}$ & $0,54 \mathrm{a}$ & $0,99 \mathrm{ab}$ \\
Mondial & $13,30 \mathrm{c}$ & $77,50 \mathrm{ab}$ & $0,11 \mathrm{~b}$ & $0,04 \mathrm{~b}$ & $0,49 \mathrm{a}$ & $0,76 \mathrm{c}$ \\
\hline $\mathrm{CV}(\%)$ & 5,70 & 6,20 & 27,80 & 33,40 & 12,70 & 5,01 \\
\hline
\end{tabular}

Médias seguidas de mesma letra nas colunas não diferem entre si pelo teste Tukey a 5\% de probabilidade de erro. 'Porcentagem da matéria fresca (means followed by the same letter, in column, do not differ by the Tukey test at $5 \%$ of probability; ${ }^{1}$ Percentage of fresh mass).

Asterix $(5,94)$ e Mondial $(4,88)$. Assim, os valores relatados por Robles (2003) e Feltran et al. (2004) são maiores que os observados no presente trabalho. Contudo, de acordo com Pereira (1987), menor valor de sólidos solúveis não é indicativo de baixa qualidade.

Não houve diferença significativa entre as cultivares quanto aos valores de acidez titulável (Tabela 1), demonstrando que a quantidade de ácidos orgânicos presentes na polpa dos tubérculos de batata não difere entre as cultivares. Estes dados estão de acordo com os obtidos por Feltran et al. (2004) e Robles (2003) que também não observaram diferenças estatísticas para essa variável entre a maioria das cultivares estudadas.

A cultivar Markies apresentou relação sólidos solúveis/acidez titulável mais elevada, embora não tenha diferido estatisticamente das cultivares Asterix e Atlantic (Tabela 1). Esse valor, geralmente, é um bom indicativo do sabor, pois dá uma boa idéia do equilíbrio entre esses dois componentes.
Os maiores valores de $\mathrm{pH}$ da polpa foram observados nas cultivares Markies e Atlantic, embora a última não tenha diferido da cultivar Asterix (Tabela 1). Considerando que, os valores de $\mathrm{pH}$ da polpa dos tubérculos de todas as cultivares estudadas estavam acima de 6,0 , nota-se que os tubérculos se encontravam em bom estado de maturação e conservação, pois os valores de $\mathrm{pH}$ ótimos para a ação de enzimas que degradam o amido são menores (Nardin, 2009). Os valores observados neste trabalho foram superiores aos relatados por Feltran et al. (2004), contudo, semelhantes aos verificados por Nardin (2009). Foi observada correlação positiva $(\mathrm{r}=0,82 ; p<0,001)$ entre o $\mathrm{pH}$ da polpa e teor de matéria seca, ou seja, quanto maior o teor de matéria seca, menor a acidez da polpa.

As cultivares Atlantic e Markies apresentaram maiores teores de matéria seca, sendo que a Markies não diferiu da Asterix (Tabela 2). Tubérculos com maiores teores de carboidratos e com menores teores de água são mais adequados à fritura e ao preparo de purês (Pereira et al., 2005), favorece o rendimento da fritura e a produção de chips, proporcionando menor retenção de óleo e garantindo a crocância do produto final (Melo, 1999). Cultivares com menor teor de matéria seca em seus tubérculos como Agata e Mondial, são mais firmes no cozimento, sendo indicadas para a preparação de pratos assados onde é essencial a manutenção de sua forma (Pereira, 1987). Melo (1999) relata que para a obtenção de tubérculos com alto teor de matéria seca, deve-se plantar cultivares que tenham essa característica genética, mas que em alguns casos somente essa medida não é suficiente, pois o acúmulo de matéria seca nos tubérculos pode ser alterado por diversas condições ambientais.

Os teores de amido (base seca) variaram de 84,8\% na cultivar Atlantic a $72,2 \%$ na Agata (Tabela 2). Essa variável correlacionou-se positivamente com o teor de matéria seca $(\mathrm{r}=0,39$; 
Tabela 3. Coloração da polpa e após a fritura na forma de palitos e chips de tubérculos de cultivares de batata, produzidos na safra de inverno (flesh and frying color in sticks and potato chips of tubers of potato cultivars produced in the winter cropping season). Botucatu, FCA-UNESP, 2008.

\begin{tabular}{lccccc}
\hline Cultivares & $\boldsymbol{L}^{*}$ & $\boldsymbol{a}^{*}$ & $\boldsymbol{b}^{*}$ & Ângulo hue $\left({ }^{*} \boldsymbol{h}\right)$ & Chroma $\left(\boldsymbol{C}^{*}\right)$ \\
\hline Agata & 60,7 & $-2,3$ & 20,5 & 96,1 & 20,7 \\
Asterix & 61,2 & $-4,6$ & 17,6 & 103,5 & 18,2 \\
Atlantic & 73,0 & $-4,5$ & 15,6 & 106,1 & 16,2 \\
Markies & 71,0 & $-5,7$ & 22,1 & 104,4 & 22,8 \\
Mondial & 61,6 & $-2,9$ & 21,6 & 98,1 & 21,8 \\
\hline \multicolumn{5}{c}{ Fritas na forma de chips } \\
\hline Agata & 35,7 & $-2,9$ & 10,5 & 105,4 \\
Asterix & 61,4 & $-4,0$ & 17,8 & 103,0 & 11,0 \\
Atlantic & 51,2 & $-0,6$ & 13,0 & 94,1 & 18,2 \\
Markies & 50,8 & $-4,5$ & 21,9 & 101,9 & 22,4 \\
Mondial & 45,8 & $-1,5$ & 20,2 & 95,6 & 20,3 \\
\hline \multicolumn{5}{c}{ Polpa fresca } \\
\hline Agata & $59,8 \mathrm{~b}$ & $-3,7$ & 18,7 & $101,2 \mathrm{a}$ \\
Asterix & $66,2 \mathrm{ab}$ & $-3,5$ & 19,8 & $100,1 \mathrm{a}$ & $20,1 \mathrm{~b}$ \\
Atlantic & $66,1 \mathrm{ab}$ & $-2,5$ & 13,6 & $100,4 \mathrm{a}$ \\
Markies & $68,6 \mathrm{a}$ & $-4,5$ & 25,0 & $100,2 \mathrm{a}$ & $13,8 \mathrm{c}$ \\
Mondial & $63,0 \mathrm{ab}$ & $-3,7$ & 20,2 & $100,4 \mathrm{a}$ & $25,4 \mathrm{a}$ \\
\hline CV(\%) & 5,0 & - & - & $0,5 \mathrm{ab}$ \\
\hline
\end{tabular}

Médias seguidas de mesma letra nas colunas (para cor da polpa) não diferem entre si pelo teste Tukey a $5 \%$ de probabilidade de erro (means followed by the same letter, in column (for flesh color), do not differ by the Tukey test at $5 \%$ of probability).

$p<0,10)$, confirmando os relatos de Fontes \& Finger (2000) e Freitas et al. (2006) de que o amido representa de 60 a $80 \%$ da matéria seca dos tubérculos. Além disso, possui influência direta com a textura dos produtos processados (Pereira, 2003).

Os principais açúcares encontrados na batata são os redutores (glicose e frutose) e não redutores (sacarose), os quais têm valores variados, que oscilam entre épocas de plantio, entre produtores e cultivares (Robles, 2003). O teor de açúcares totais foi semelhante nas cultivares Markies, Asterix e Atlantic, sendo que esta última não diferiu das outras duas (Tabela 2). Já a concentração de açúcares redutores, nos tubérculos das cinco cultivares, variou de $0,04 \%$ a $0,18 \%$ da matéria fresca (Tabela 2). As cultivares Markies e Asterix apresentaram maiores teores de açúcares redutores, contudo diferindo apenas da cultivar Mondial. As pequenas diferenças entre as cultivares quanto aos teores de açúcares redutores nos tubérculos podem ser atribuídas aos altos valores de coeficiente de variação.

Stark et al., (2003) relatam que batatas para serem aceitas para o processamento, devem possuir teores de açúcares redutores geralmente abaixo de $0,035 \%$ da massa fresca para processamento na forma de chips e $0,12 \%$ quando processadas na forma de palitos. Assim, segundo esses autores, nas condições de cultivo de inverno, nenhuma das cultivares avaliadas apresentam teores de açúcares redutores adequados para processamento na forma de chips e apenas as cultivares Agata, Atlantic e Mondial apresentam teores de açúcares redutores adequados para o processamento na forma de palitos.

Não foram observadas diferenças entre o teor de fibras totais nos tubérculos das cultivares estudadas (Tabela 2). Os maiores teores de cinzas foram obtidos nos tubérculos da cultivar Atlantic, a qual diferiu estatisticamente das culti- vares Agata, Asterix e Mondial (Tabela 2). Os teores de cinzas nos tubérculos da cultivar Atlantic e Markies foram superiores aos obtidos por Quadros et al. (2009), que observaram teores da ordem de $0,93 \%$.

Os atributos de cor das batatas fritas encontram-se na Tabela 3. As cores foram expressas em termos de três atributos: luminosidade $\left(L^{*}\right)$, que diferencia cores claras de escuras e seu valor varia de zero para cores escuras a 100 para cores claras; ângulo hue $\left({ }^{\circ} h\right)$ que é indicativo de tonalidade e, saturação ou chroma que define a intensidade de cor $\left(C^{*}\right)$ (Mcguire, 1992). A cultivar Atlantic apresentou palitos mais claros (maiores valores de $L^{*}$ ) que as demais cultivares, enquanto que, os chips de cor mais clara foram obtidos com a cultivar Asterix e Atlantic. De maneira geral, houve a tendência de coloração mais clara nos palitos que nos chips, com exceção da cultivar Asterix, em que a forma de processamento não teve efeito sobre a luminosidade do produto final.

Coleman (2004) classificou a cor da batata após a fritura como sendo de qualidade inaceitável $\left(\mathrm{L}^{*}<55\right)$; aceitável $\left(L^{*} \geq 55\right.$ e $\left.\leq 70\right)$ e de alta qualidade $\left(\mathrm{L}^{*}>70\right)$. Assim, de acordo com esse autor, as cultivares Atlantic e Markies apresentaram palitos de alta qualidade e, as demais apresentaram palitos de coloração aceitável. No entanto, quando processada na forma de chips, apenas a cultivar Asterix apresentou chips de cor aceitável, enquanto todas as demais apresentaram chips de cor inaceitável (Coleman, 2004). Resultados semelhantes foram obtidos por Müller et al. (2009) em tubérculos da cultivar Asterix produzidos nas condições de cultivo de primavera e outono.

Embora os teores de açúcares redutores estejam normalmente correlacionados com os valores de cor dos chips (Coelho et al., 1999; Feltran et al., 2004), cultivares com teores de açúcares redutores considerados inadequados para a fritura na forma de palitos (Asterix e Markies) e chips (Agata, Asterix, Atlantic, Markies e Mondial) apresentaram tanto palitos (Agata, Asterix e Mondial) como chips (Asterix) de cor aceitável, além de palitos com cor de alta qualidade (Atlantic e Markies). Isso 
provavelmente está relacionado com a concentração de aminoácidos e polifenóis totais que também têm demonstrado certa influência sobre a intensidade de coloração das batatas fritas (Zorzella et al., 2003; Freitas et al., 2006).

De acordo com a seqüência CIELAB hue (Mcguire, 1992), que define a cor vermelha como $0^{\circ} \mathrm{h}$, amarelo como $90^{\circ} \mathrm{h}$, verde como $180^{\circ} \mathrm{h}$ e azul como $270^{\circ} \mathrm{h}$, as cultivares estudadas apresentaram palitos e chips de coloração amarelada. As cultivares Agata e Mondial apresentaram palitos com tonalidade mais próxima da amarela (menor valor de ângulo hue). Já para os chips as cultivares Atlantic $\left(94,1^{\circ} h\right)$ e Mondial $\left(95,6^{\circ} h\right)$ apresentaram menores valores de ângulo hue, ou seja, tonalidade mais amarelada (Tabela 3). Rodriguez-Saona \& Wrolstad (1997) estudando a influência da composição de tubérculos de batata na qualidade de cor dos chips, verificaram que as tonalidades de cor dos chips variaram de amarelo-alaranjado $\left(75^{\circ} h\right)$ a avermelhado $\left(63^{\circ} h\right)$.

O chroma $\left(C^{*}\right)$ define a intensidade de cor, ou seja, valores próximos a zero são indicativos de cores neutras (branco e/ou cinza) e valores ao redor de 60 indicam cores vívidas e/ou intensas. As cores mais intensas dos chips e palitos (maiores valores de $C^{*}$ ) foram observadas nas cultivares Markies $\left(C^{*}=22,8\right.$ nos palitos; $C^{*}=22,4$ nos chips) e Mondial ( $C^{*}=21,8$ palitos; $C^{*}=20,3$ chips , ou seja, essas cultivares apresentaram palitos e chips de coloração amarela mais intensa que as demais. A menor intensidade de cor foi obtida nos palitos das cultivares Atlantic $\left(C^{*}=16,2\right)$ e Asterix $\left(C^{*}=18,2\right)$ e nos chips das cultivares Agata $\left(C^{*}=11,0\right)$ e Atlantic $\left(C^{*}=13,3\right)$ (Tabela 3). Esses resultados demonstram que as cultivares Markies e Mondial proporcionaram chips e palitos de coloração mais intensa, os quais são rejeitados pelo mercado consumidor (Menéndez et al., 2002; Pereira et al., 2007). Já as cultivares Atlantic, Asterix e Agata, apresentaram fritura de cor amarelada, porém, de menor intensidade, ou seja, mais clara (menores valores de $\left.C^{*}\right)$, característica essa, adequada para processamento (Pereira et al., 2007).

Diferentes intensidades de cor foram observadas por Rodriguez-Saona \&
Wrolstad (1997) em chips de cinco cultivares de batata, as quais variaram entre cores mais intensas $\left(C^{*}=28\right)$ a cores de menor intensidade $\left(C^{*}=19\right)$. Embora esses autores tenham obtido chips com cor mais intensa, a tonalidade amarela dos chips produzidos foi inferior às observadas no presente experimento.

A cor da polpa dos tubérculos frescos também é um fator determinante da qualidade dos produtos processados. Os valores do ângulo hue foram indicativos de que todas as cultivares apresentaram polpa de coloração amarelada (valores próximos de $100^{\circ} h$ ). Porém, a cultivar Atlantic teve como característica apresentar polpa de cor clara (menores valores de $C^{*}$ ), pois, mesmo apresentando valores semelhantes às demais cultivares para o ângulo hue, a intensidade da cor foi significativamente menor $\left(C^{*}=13,8\right)$, enquanto que as cultivares Markies e Mondial apresentaram polpa de cor amarelo mais escuro ou mais intenso, como pode ser observado pelos maiores valores de $C^{*}$ (Tabela 3 ). Assim, nota-se que a cor da polpa (branco ou amarelo) influiu na cor do produto final após a fritura, uma vez que a cultivar Atlantic, de polpa mais clara, apresentou tanto palitos como chips mais claros (menores valores de $C^{*}$ e valores de $L^{*}$ relativamente elevados), enquanto que Markies e Mondial de polpa amarelo intenso apresentaram palitos e chips de coloração mais intensa/escura (maiores valores de $C^{*}$ ).

Rodriguez-Saona \& Wrolstad (1997) relataram que diferença em apenas uma dimensão de cor ( $L^{*}$, ângulo hue e chroma) é suficiente para proporcionar diferentes características visuais nos chips. Como relatado por estes autores, apenas o teor de açúcares redutores, não é suficiente para explicar ou predizer a qualidade da coloração da batata frita, já que cultivares com diferentes teores de açúcares redutores apresentaram coloração de chips similares. No presente trabalho foi verificado que as cultivares Markies e Mondial, que apresentaram o maior $(0,18 \%)$ e menor $(0,04 \%)$ teor de açúcares redutores, respectivamente, apresentaram palitos de cor aceitável (Mondial) e de alta qualidade (Markies). Nesse sentido, tem sido demonstrada a influência de alguns aminoácidos e compostos fenólicos na intensidade da coloração das fritas (Zorzella et al., 2003; Freitas et al., 2006), o que torna fundamental avaliar a cor da fritura para uma conclusão mais apurada, uma vez que a cor é considerada um dos parâmetros mais importantes na definição da qualidade das batatas fritas (Pedreschi et al., 2007).

Embora não tenha sido avaliada a textura do material após a fritura, com base em observações visuais constatouse que as cultivares Atlantic e Markies ficaram com aspectos de mais crocantes (absorveram menos óleo), enquanto as cultivares Agata e Mondial ficaram com aparência de mole e encharcada. Isso provavelmente está relacionado com os maiores teores de sólidos solúveis e matéria seca observados nos tubérculos das cultivares Markies e Atlantic (Tabelas 1 e 2).

Diante dos resultados obtidos concluiu-se que os tubérculos das cultivares Mondial e Agata apresentam características adequadas para o mercado fresco, sendo indicadas para a preparação de massas e pratos assados em que é essencial a manutenção de sua forma. Markies apresenta dupla aptidão culinária, ou seja, possui qualidade adequada ao preparo de massas e fritura. Os tubérculos das cultivares Atlantic, Asterix e Markies apresentam boa qualidade de fritura, no entanto, a cultivar Markies apresenta polpa dos tubérculos, palitos e chips de coloração amarela mais intensa, comparada às demais cultivares.

\section{AGRADECIMENTOS}

Ao CNPq pela concessão de bolsa de Mestrado ao primeiro autor e de Produtividade em Pesquisa ao segundo autor. Ao Grupo Ioshida pela concessão da área para condução do experimento de campo e, à Associação Brasileira da Batata (ABBA) pelo auxílio financeiro.

\section{REFERÊNCIAS}

ANDREU MA; PINTO CABP; SIMON GA. 2007. Genetic markers for processing traits in potato. Crop Breeding and Applied Biotechnology 7: 67-73.

AOAC. 1997. Official methods of analysis of the Association of Analytical Chemists 
International. 16 ed. Gaytheersburg: AOAC. $1015 \mathrm{p}$.

AOAC. 2000. Official methods of analysis of the Association of Analytical Chemists International. 17 ed. Gaythersburg: AOAC. $1141 \mathrm{p}$.

BRASIL. 2005. Ministério da Saúde. Agência Nacional de Vigilância Sanitária. Métodos Físicos e Químicos para Análise de Alimentos 4. ed. Brasília: Ministério da Saúde, 1018 p.

BREGAGNOLI M. 2006. Qualidade e produtividade de cultivares de batata para indústria sob diferentes adubações. Piracicaba: USP-ESALQ. 141p. (Tese doutorado).

CHITARRA MIF; CHITARRA AB. 2005. Póscolheita de frutas e hortaliças: fisiologia e manuseio. 2 ed. Lavras: UFLA. 785 p.

COELHO AHR; VILELA ER; CHAGAS SJR. 1999. Qualidade de batata (Solanum tuberosum L.) para fritura, em função dos níveis de açúcares redutores e amido, durante $\mathrm{o}$ armazenamento refrigerado e à temperatura ambiente com atmosfera modificada. Ciência e Agrotecnologia 23: 899-910.

COLEMAN WK. 2004. Comparative performance of the $L^{*} a * b *$ color space and North American color charts for determining chipping quality in tubers of potato (Solanum tuberosum L.). Canadian Journal of Plant Science 84: 291-298.

FELTRAN JC; LEMOS LB; VIEITES RL. 2004. Technological quality and utilization of potato tubers. Scientia Agricola 61: 598-603.

FONTES PCR; FINGER FL. 2000. Pós-colheita do tubérculo de batata. Viçosa: UFV. 32p.

FREITAS ST; BISOGNIN DA; GÓMEZ ACS; SAUTTER CK; COSTA LC; RAMPELOTTO MV. 2006. Qualidade para processamento de clones de batata cultivados durante a primavera e outono no Rio Grande do Sul. Ciência Rural 36: $80-85$.

MCGUIRE RG. 1992. Reporting of objective color measurements. Horticultural Science
27: 1254-1255.

MELO PE. 1999. Cultivares de batata potencialmente úteis para o processamento na forma de fritura no Brasil e manejo para obtenção de tubérculos adequados. Informe Agropecuário 20: 112-119.

MENÉNDEZ CM; RITTER E; SCHÄFERPREGL R; WALKEMEIER B; KALDE A; SALAMINI F; GEBHARDT C. 2002. Cold sweetening on diploid potato: Mapping quantitative trait loci and candidate genes. Genetics 162: 1425-1434.

MORENO JD. 2000, 01 de setembro. Calidad de la papa para usos industriales. Disponível em: www.redepapa.org/calidadpapa.pdf/

MÜLLER DR; BISOGNIN DA; ANDRIOLO JL; MORIN JUNIOR GR; GNOCATO FS. 2009. Expressão dos caracteres e seleção de clones de batata nas condições de cultivo de primavera e outono. Ciência Rural 39: 1327-1334.

NARDIN I. 2009. Qualidade, suscetibilidade ao esverdeamento e aptidão culinária de cultivares de batata (Solanum tuberosum L.). Botucatu: UNESP-FCA. 96p. (Monografia especialização).

NELSON NA. 1944. A photometric adaptation of Somogy method for determination of glucose. Journal of Biological Chemistry 153: 375-390.

PAPADAKIS SE; ABDUL-MALEK S; KAMDEM RE; YAM KL. 2000. A versatile and inexpensive technique for measuring color of foods. Food Technology 54: 48-51.

PEDRESCHI F; LEON J; MERY D; MOYANO P; PEDRESCHI R; KAACK K; GRANBY K. 2007. Color development and acrylamide content of pre-dried potato chips. Journal of food Engineering 79: 786-793.

PEREIRA AS. 1987. Composição química, valor nutricional e industrialização. In: REIFSCHNEIDER FJB (eds). Produção de batata. Brasília: Linha Gráfica. p. 12-28.
PEREIRA AS. 2003. Melhoramento genético. In: PEREIRA AS; DANIELS J (eds). $O$ cultivo da batata na região sul do Brasil. Brasília: Embrapa Informação Tecnológica, p.105-124.

PEREIRA AS; FRITSCHE NETO R; SILVA RS; BENDER CI; SCHÜNEMANN AP; FERRI NML; VENDRUSCOLO JL. 2007. Genótipos de batata com baixo teor de açúcares redutores. Horticultura Brasileira 25: 220-223.

PEREIRA EMS; LUZ JMQ; MOURA CC. 2005. A batata e seus beneficios nutricionais. Uberlândia: EDUFU. 60 p.

QUADROS DA; IUNG MC; FERREIRA SMR; FREITAS RJS. 2009. Composição química de tubérculos de batata para processamento, cultivados sob diferentes doses e fontes de potássio. Ciência e Tecnologia de Alimentos 29: 316-323.

ROBLES WGR. 2003. Dióxido de carbono via fertirrigação em batateira (Solanum tuberosum L.) sob condições de campo. Piracicaba: USP ESALQ. 160 p. (Tese doutorado).

RODRIGUES-SAONA LE; WROLSTAD RE. 1997. Influence of potato composition on chip color quality. American Potato Journal 74: 87-106.

SALAMONI AT; PEREIRA AS; VIEGAS J; CAMPOS AD; CHALA CSA. 2000. Variação genética de açúcares redutores e matéria seca e suas correlações com características agronômicas em batata. Pesquisa Agropecuária Brasileira 35: 144-145.

STARK JC; OLSEN N; KLEINKOPF GE; LOVE SL. 2003. Tuber quality. In: STARK JC; LOVE SL (eds). Potato production systems. Aberdeen: University of Idaho. p. 329-343.

ZORZELLA CA; VENDRUSCOLO JLS; TREPTOW RO; ALMEIDA TL. 2003. Caracterização física, química e sensorial de genótipos de batata processados na forma chips. Brazilian Journal of Food Technology 6: 15-24. 